\title{
Diagnosis despite clinical ambiguity: physicians' perspectives on the rise in Autism Spectrum disorder incidence
}

\author{
Michael Davidovitch ${ }^{1,2^{*}}$ (D), Dorit Shmueli ${ }^{3}$, Ran Shmuel Rotem ${ }^{2,4}$ and Aviva Mimouni Bloch 5,6
}

\begin{abstract}
Background: To provide insight on physicians' perspectives concerning recent changes in the incidence and diagnostic process of Autism Spectrum Disorder (ASD) compared to other mental and neurodevelopmental disorders.

Method: A questionnaire was sent to 191 specialists in child neurology and child development, and 200 child psychiatrists in Israel. Information was collected on professional background, as well as on physicians' opinions concerning the accuracy and rate of ASD diagnosis compared to that of cerebral palsy (CP), mental illness, and Attention Deficit Hyperactivity Disorder (ADHD). For each closed-ended question, a global chi-square test for categorical variables was performed.
\end{abstract}

Results: 115 (60.2\%) of specialists in child neurology and development, and 59 (29.5\%) of child psychiatrists responded. Most physicians (67.2\%) indicated that there was a moderate/significant increase in the incidence of ASD, which was higher than similar responses provided for CP $(2.9 \%, p<0.01)$ and mental illnesses $(14.4 \%, p<0.01)$, and similar to responses provided for $\operatorname{ADHD}(70.1 \%, p=0.56) .52 .8 \%$ of physicians believed that in more than $10 \%$ of clinical assessments, an ASD diagnosis was given despite an inconclusive evaluation (CP: 8.6\%, $p<0.01$; mental illnesses: 25.8\%, $p=0.03 ;$ ADHD: $68.4 \%, p=0.03$ ).

Conclusion: The clinicians perceive both ASD and ADHD as over-diagnosed disorders. The shared symptomology between ASD and other disorders, coupled with heightened awareness and public de-stigmatization of ASD and with the availability of ASD-specific services that are not accessible to children diagnosed with other conditions, might lead clinicians to over-diagnose ASD. It is advisable to adopt an approach in which eligibility for treatments is conditional on function, rather than solely on a diagnosis. The medical community should strive for accurate diagnoses and a continuous review of diagnostic criteria.

Keywords: Autism Spectrum disorder, Diagnosis, Physicians' opinion

\footnotetext{
* Correspondence: davidom@netvision.net.il

'Child Development, Medical Division and Research Institute, Maccabi Healthcare Services, 27 Hamered St., 6812509 Tel Aviv, Israel

${ }^{2}$ Kahn-Sagol-Maccabi Research and Innovation Institute, Maccabi Healthcare Services, 4 Koifmann St., 6801296 Tel Aviv, Israel

Full list of author information is available at the end of the article
} 


\section{Background}

Autism Spectrum Disorder (ASD) is a severe disorder with pervasive difficulties in social interaction, restricted communication, and repetitive patterns of behavior [1], resulting in significant personal, familial, and societal impacts. ASD prevalence has increased dramatically in the last three decades. In the U.S., the prevalence at 8 years of age increased from $0.2 \%$ during the nineties [2] to recent estimates of $1.85 \%$ [3]. Reports from Israel show a similar trend, with cumulative incidence estimates of $1.3 \%$ in 2018 [4]. This steady rise in ASD is uncommon for severe developmental disorders. While a genetic basis for the disorder is well documented with hundreds of genes identified as potential etiologic contributors [5], estimates suggest that inheritable and de novo gene variations only account for $10-20 \%$ of ASD cases [6]. Recent research has also associated other factors with ASD risk, including advanced parental age, birth complications, maternal pregnancy-related factors, and environmental influences [7]. However, while the cumulative effect of the above factors likely contributes to the rising trend in ASD incidence, ASD has no biological markers, and the diagnosis relies solely on the evaluation of developmental history, questionnaires, clinical observations, and semi-structured tests. This has led some researchers to suggest that there are other, extrinsic determinants related to seeking a diagnosis and to the diagnostic process itself that account for the increasing trend in ASD. These include diagnostic expansion, the inclusion of other neurodevelopmental disorders, diagnostic substitution, diagnostic awareness, diagnostic coupling to services and entitlements, diagnostic resolution, and overdiagnosis [8]. To provide some insight on physicians' perspectives concerning the possible effects of the above factors, we surveyed specialists in child neurology and development and child psychiatry on recent changes in the incidence and diagnostic process of ASD compared to other mental and neurodevelopmental disorders.

\section{Methods}

A questionnaire was designed to obtain physicians' opinions on changes in incidence and diagnostic practices for the following conditions: ASD, cerebral palsy (CP), mental illness (anxiety, depression, or schizophrenia), and Attention Deficit Hyperactivity Disorder (ADHD). In the last section, physicians were asked to make recommendations for changes in policy that the Israeli Ministry of Health should implement regarding ASD. Questions are listed in Table 1. The questionnaire was distributed in January and February 2020 to 191 specialists in child neurology and child development, and to 200 child psychiatrists, primarily via email (due to low response rate in the psychiatrists' group, a paper questionnaire was also distributed to them during a scientific conference). Contact information for the physicians was obtained from the Child Neurology and Development Association and the Child Psychiatry Association, which are both parts of the Israeli Medical Association, and includes most of the specialists in these fields in Israel. The responses were anonymized and returned to the first author of this article.

\section{ASD diagnosis process}

The ASD diagnosis process in Israel must adhere to the following guidelines: 1) the diagnosis should be performed

Table 1 Study Questionnaire

\begin{tabular}{|c|c|c|c|c|c|c|c|}
\hline \multirow{2}{*}{$\overline{1}$} & \multirow{2}{*}{$\begin{array}{l}\text { Question } \\
\text { What is your area of specialty }\end{array}$} & \multicolumn{6}{|c|}{ Possible responses } \\
\hline & & \multicolumn{2}{|c|}{$\begin{array}{l}\text { Child neurology } \\
\text { and development }\end{array}$} & \multicolumn{4}{|c|}{ Child psychiatry } \\
\hline 2 & How many years have you been working in your field? & \multicolumn{2}{|l|}{ up to 5} & \multicolumn{3}{|l|}{$5-10$} & above 10 \\
\hline 3 & As part of your work, do you diagnose children with ASD? & \multicolumn{2}{|l|}{ Yes } & \multicolumn{3}{|l|}{ No } & \\
\hline 4 & Where does the diagnosis process take place? & \multicolumn{2}{|l|}{ Public clinic } & \multicolumn{3}{|l|}{ Private clinic } & Both \\
\hline 5 & $\begin{array}{l}\text { What percentage of your time at work do you spend on ASD } \\
\text { diagnosis? }\end{array}$ & \multicolumn{2}{|l|}{ up to $10 \%$} & \multicolumn{3}{|l|}{$10-50 \%$} & above $50 \%$ \\
\hline 6 & $\begin{array}{l}\text { In your opinion, has there been an increase in the number of } \\
\text { children diagnosed with ASD? }\end{array}$ & significant & modest & low & \multicolumn{2}{|l|}{ no } & do not know \\
\hline 7 & $\begin{array}{l}\text { Do you think that there is an increase in the percentage of ASD } \\
\text { diagnoses given despite the clinical evaluation being inconclusive? }\end{array}$ & significant & modest & low & \multicolumn{2}{|l|}{ no } & do not know \\
\hline 8 & $\begin{array}{l}\text { Of all ASD diagnoses, what percentage of diagnoses do you think } \\
\text { were given despite having some doubt? }\end{array}$ & $1-10 \%$ & $11-20 \%$ & $21-30 \%$ & $31-40 \%$ & $41-50 \%$ & Above 50\% \\
\hline 9 & $\begin{array}{l}\text { In cases when an ASD diagnosis is given despite the evaluation } \\
\text { being inconclusive, what do you think is the main reason for this? }\end{array}$ & $\begin{array}{l}\text { substitution } \\
\text { of diagnosis }\end{array}$ & $\begin{array}{l}\text { to grant } \\
\text { autism } \\
\text { benefits }\end{array}$ & $\begin{array}{l}\text { diagnostic } \\
\text { expansion }\end{array}$ & $\begin{array}{l}\text { familial } \\
\text { pressure }\end{array}$ & $\begin{array}{l}\text { diagnostic } \\
\text { awareness }\end{array}$ & other (explain) \\
\hline
\end{tabular}

Questions 7 and 8 were repeated for cerebral palsy (CP); Attention Deficit Hyperactivity Disorder (ADHD); and anxiety, depression, and schizophrenia (the latter 3 conditions were subsequently grouped to a broader mental illness category); 
by a pediatric psychiatrist, pediatric neurologist, or a developmental pediatrician, and must include detailed physical, neurological, and developmental evaluations; 2) the ASD diagnosis must be based on the Diagnostic and Statistical Manual of Mental Disorders, 5th Edition (DSM-5) criteria [1];3) an independent assessment by a developmental or clinical psychologist must confirm ASD case status; 4) the final report should include a detailed description of the child's developmental and cognitive status; and 5) inputs from other medical specialists, including speech and language specialists, occupational therapists, and social workers should be included in the evaluation process as needed. The ASD evaluations for children up to the age of 6 are multidisciplinary and take place in child development centers. For older children, the evaluations are usually performed by child psychiatrists or neurologists and child psychologists through the Health Maintenance Organizations, or in hospital-based centers for ASD diagnosis. Some of the assessments take place in private clinics due to long waiting for public services.

\section{Statistical analysis}

For each closed-ended question, a global chi-square test for categorical variables was performed to determine if statistically significant differences were observed for physicians' responses across the different neurodevelopmental and mental conditions considered. If statistically significant results were obtained in the global test, post hoc pairwise comparisons using multiple $2 \times 2$ contingency tables were used to specifically compare physicians' responses for ASD to each of the other disorders considered.

\section{Results}

Out of 191 experts in child neurology and development and 200 psychiatrists that were contacted, 115 (60.2\%) and 59 (29.5\%) provided responses, respectively, for a total of 174 physicians (44\%) that completed the survey. Most physicians had more than 5 years of practice experience ( $86 \%$ of experts in child neurology and development; $75 \%$ of child psychiatrists), overall, $90 \%$ of them diagnosed ASD in their practice, and $86 \%$ worked in both public and private clinics.

The majority of physicians (67.2\%) indicated that there is a moderate or significant increase in the incidence of ASD diagnosis, which was statistically significantly different compared to the number of similar responses provided for $\mathrm{CP}(2.9 \%, p<0.01)$ and other mental disorders $(14.4 \%, \mathrm{p}<0.01)$, however not compared to ADHD $(70.1 \%, p=0.56)$ (Table 2). Additionally, more than half of the physicians (52.8\%) believed that in more than $10 \%$ of clinical evaluations, an ASD diagnosis was given despite the assessments being inconclusive, an estimate which was statistically significantly different than the number of similar responses provided for CP $(8.6 \%, p<$ $0.01)$ and mental illness $(25.8 \%, p=0.03)$, as well as ADHD (68.4\%, $\mathrm{p}=0.03$ ) (Table 3). More than a third of the physicians believed that the reason why clinicians diagnosed ASD in inconclusive cases was because of benefits that children with ASD are entitled to receive (Table 4).

Ninety-two (53\%) physicians wrote comments regarding ASD regulations, diagnoses, and services. The main suggestions included: 1 . Providing services, treatments, and benefits according to the child's functional level and for specific deficits in development and not solely based on diagnostic label; 2 . Children younger than 3 years of age should receive a temporary diagnosis of ASD with reevaluation at the age of three, since ASD diagnosis may resolve in some children that received ASD diagnosis at a very young age; 3 . Permission to diagnose ASD should only be given to highly knowledgeable and experienced psychiatrists, neurologists, psychologists, and other health professionals; 4. Implementation of stricter criteria for ASD diagnosis.

\section{Discussion}

This study describes physicians' opinions regarding ASD diagnosis in comparison to other behavioral and mental

Table 2 Physician response to the question of uncertain diagnoses

\begin{tabular}{|c|c|c|c|c|c|c|c|c|c|c|c|c|}
\hline & \multicolumn{12}{|c|}{ Is there an increase in uncertain diagnosis? } \\
\hline & \multicolumn{2}{|c|}{ Significant Increase } & \multicolumn{2}{|c|}{ Moderate Increase } & \multirow{2}{*}{ 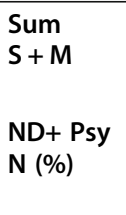 } & \multicolumn{2}{|c|}{ Low Increase } & \multicolumn{2}{|c|}{ No Increase } & \multicolumn{2}{|c|}{$\begin{array}{l}\text { No answer / } \\
\text { Do not know }\end{array}$} & \multirow{2}{*}{$\begin{array}{l}\text { Sum } \\
\text { Low+No+ } \\
\text { No answer } \\
\text { ND+ Psy } \\
\text { N (\%) }\end{array}$} \\
\hline & $\begin{array}{l}\text { ND } \\
N \\
\text { (\%) }\end{array}$ & $\begin{array}{l}\text { Psy } \\
\text { N } \\
(\%) \\
\end{array}$ & $\begin{array}{l}\text { ND } \\
N \\
\text { (\%) }\end{array}$ & $\begin{array}{l}\text { Psy } \\
\text { N } \\
\text { (\%) }\end{array}$ & & $\begin{array}{l}\text { ND } \\
N \\
\text { (\%) }\end{array}$ & $\begin{array}{l}\text { Psy } \\
\mathrm{N} \\
(\%)\end{array}$ & $\begin{array}{l}\text { ND } \\
N \\
\text { (\%) }\end{array}$ & $\begin{array}{l}\text { Psy } \\
\text { N } \\
\text { (\%) }\end{array}$ & $\begin{array}{l}\text { ND } \\
N \\
\text { (\%) }\end{array}$ & $\begin{array}{l}\text { Psy } \\
\text { N } \\
\text { (\%) }\end{array}$ & \\
\hline ASD & $36(31.3)$ & $21(35)$ & $38(33)$ & $22(36.7)$ & $117(67.2)$ & $21(18.3)$ & $6(10)$ & $13(18.3)$ & $4(6.7)$ & $7(6.1)$ & $6(10)$ & $57(32.8)$ \\
\hline$C P$ & $1(0.9)$ & 0 & $3(2.6)$ & $1(1.7)$ & $5(2.9)$ & $15(13)$ & $2(3.3)$ & $76(66.1)$ & 6 10) & $20(17.4)$ & $50(83.3)$ & $169(97.1)$ \\
\hline Mental Illness & $6(5.2)$ & $1(1.7)$ & $6(5.2)$ & $12(20)$ & $25(14.4)$ & $22(19.1)$ & $16(26.7)$ & $15(13)$ & $22(36.7)$ & $66(57.4)$ & $813.3)$ & $149(85.6)$ \\
\hline ADHD & $35(30.4)$ & $21(35)$ & $47(40.9)$ & $19(31.7)$ & $122(70.1)$ & $20(17.4)$ & $12(20)$ & $11(9.6)$ & $5(8.3)$ & $2(1.7)$ & $2(3.3)$ & $52(29.9)$ \\
\hline
\end{tabular}

ND Physicians expert in neurology and development, Psy Physicians expert in child psychiatry, Sum $S+M$ sum of significant and moderate response, Sum Low+No+No answer sum of low, no increase and do not know / no answer, ASD autism spectrum disorder, CP cerebral palsy, Mental illness anxiety or depression or schizophrenia, $A D H D$ attention deficit hyperactivity disorder 
Table 3 Physician response to the question of the percent of uncertain diagnoses

\begin{tabular}{|c|c|c|c|c|c|c|c|c|}
\hline & \multicolumn{8}{|c|}{ Percent of Uncertain Diagnosis } \\
\hline & Up to $10 \%$ & $11-20 \%$ & $21-30 \%$ & $31-40 \%$ & $41-50 \%$ & More than $50 \%$ & Sum Above $10 \%$ & $\begin{array}{l}\text { No answer / } \\
\text { Do not know }\end{array}$ \\
\hline ASD & 25.9 & 23.5 & 19.5 & 2.9 & 4 & 2.9 & 52.8 & 21.3 \\
\hline$C P$ & 37.4 & 5.7 & 2.3 & 0 & 0.6 & 0 & 8.6 & 54 \\
\hline Mental IIIness & 23.6 & 17.8 & 5.7 & 1.15 & 1.15 & 0 & 25.8 & 50.6 \\
\hline ADHD & 18.4 & 31.6 & 19.5 & 8.6 & 3.5 & 5.2 & 68.4 & 13.2 \\
\hline
\end{tabular}

$A S D$ autism spectrum disorder, $C P$ cerebral palsy, Mental illness anxiety or depression or schizophrenia, $A D H D$ attention deficit hyperactivity disorder. All $P$ values are for comparisons to the number of similar responses provided for the ASD group

disorders. Most physicians agreed that ASD incidence is increasing, with many attributing some of this increase to diagnoses that were given despite the clinical evaluation being inconclusive. The vast majority of the specialists who answered the survey diagnose ASD in their practice, and indeed when asked about areas with which they were less familiar, most declare that they do not know or did not respond (e.g., psychiatrists answers on cerebral palsy, Table 2).

The risk factors known to be associated with ASD development are genetic variations, perinatal [7] and environmental. Amongst the environmental factors, several toxicants, including endocrine-disrupting chemicals, air pollution, pesticides, and certain pharmaceuticals were reported to impact ASD development [9-12] . Recent reports of screen exposure and less caregiver-child play early in life have been associated with later ASD-like symptoms [13], although the direction and importance of which is unknown.

The overall increase in ASD rates over the last three decades may be the result of several interrelated factors. Awareness of ASD has tremendously increased in recent years amongst medical staff, educators, and parents. In the clinic, parents often express their fear of autism, even though their toddlers might have symptoms of more common conditions, such as expressive language delays. Additionally, symptoms of ASD overlap with those of several other conditions, including intellectual and learning disability, and developmental language disorder [14-16]. Despite the shared symptomology, access to medical and support services for children diagnosed with non-ASD conditions is typically much more limited compared to children diagnosed with ASD. In Israel, children with ASD are eligible for an extended basket of care (14 h weekly) as well as to other treatments and special education services, from their first year of life through the age of 7 . Other ASD treatments are available for older children and adolescents through the age of 18 [17]. Children diagnosed with other developmental or mental disorders largely do not benefit from these services. Thus, the shared symptomology between disorders, coupled with heightened awareness and public de-stigmatization of ASD, and with the availability of ASD-specific services that are not accessible to children diagnosed with other conditions, may have created incentives for the over-diagnosis of ASD. Analogous reasoning could be argued for the similar overall responses provided by physicians for ADHD (Tables 2 and 3), since comparable incentives, including educational accommodations and access to cognitive enhancement drugs (stimulants), are also tied to receiving an ADHD diagnostic label [18].

The sharp increase in ASD diagnosis caused the Israeli Ministry of Health to change the criteria for receiving benefits and to implement new eligibility guidelines in 2007. The new guidelines require that ASD diagnosis previously given solely by a physician specialist be independently confirmed through a second evaluation by a qualified psychologist [19]. The DSM-5 criteria, introduced in late 2013, also aimed to increase the sensitivity and specificity of ASD diagnosis [20]. Nevertheless, despite these diagnostic changes, recent data suggest that after an initial plateauing [21], ASD incidence continued to increase $[3,4]$. Therefore, it is paramount to continue efforts in precisely characterizing the signs of autism to increase the specificity and sensitivity of ASD evaluations. Continuous education of the medical team and peer learning could improve the quality of the evaluation process and enable a more detailed and accurate diagnosis.

Additionally, children with other mental and neurodevelopmental conditions, including ADHD, conduct disorder, and social anxiety, might need more treatments and individual help in school than children with high

Table 4 Physicians responses to the reasons for uncertain diagnosis in ASD

\begin{tabular}{llllllll}
\hline $\begin{array}{l}\text { Substitution } \\
\text { of diagnosis }\end{array}$ & $\begin{array}{l}\text { Autism } \\
\text { benefits }\end{array}$ & $\begin{array}{l}\text { Diagnostic } \\
\text { expansion }\end{array}$ & $\begin{array}{l}\text { Familial } \\
\text { pressure }\end{array}$ & $\begin{array}{l}\text { Diagnostic } \\
\text { awareness }\end{array}$ & $\begin{array}{l}\text { Combined } \\
\text { reasons }\end{array}$ & $\begin{array}{l}\text { Other } \\
\text { reasons }\end{array}$ \\
\hline $21(12.1)$ & $64(36.8)$ & $37(21.3)$ & $7(4)$ & $14(8)$ & $23(13.2)$ & $3(1.7)$ & $5(2.9)$ \\
\hline
\end{tabular}


functioning ASD. Since it is not feasible to provide unlimited services to all children, we highly recommend basing any decisions concerning treatment and service eligibility not only on having a diagnostic label but also on the level of functioning. Moreover, children with uncertain ASD diagnoses should be eligible for intensive initial treatments (like those with unequivocal ASD) with frequent reevaluations before a definite diagnosis is made. This is in accordance with the new Diagnostic Classification of Mental Health and Developmental Disorders of Infancy and Early Childhood (D.C.): 0-5, which suggests a diagnosis of early atypical ASD for young children with ASD features without complete symptomatology [22]. This diagnosis is less stable than ASD but will allow young children with partial symptomatology to get proper interventions.

The lack of information from the physicians that did not answer the survey is a limitation of the study. In Israel, most children with ASD are diagnosed before the age of 6 in Child Development Centers, which could explain the higher survey response rate of child neurology and development specialists who more often work in these centers.

\section{Conclusions}

Our survey of specialists in child development, neurology and psychiatry indicated that most physicians believed that ASD incidence is increasing, with some of this increase attributable to diagnoses given despite the clinical evaluation being inconclusive. Decision-makers are advised to adopt an approach that services should be gated by function regardless of diagnosis in determining eligibility for treatments and services. The medical community, for its part, must strive to improve diagnostic accuracy and for continuous review of diagnostic criteria.

\section{Abbreviations}

ASD: Autism spectrum disorder; CP: Cerebral palsy; ADHD: Attention deficit hyperactivity disorder

\section{Acknowledgements}

The authors thank Lora Salomidou and Lior Davidovitch for editing the manuscript.

\section{Authors' contributions \\ All authors contributed to the study conception and design. Material preparation, data collection, and analysis were performed by MD, DS, RSR, and AMB. The first draft of the manuscript was written by MD, and all authors commented on previous versions of the manuscript. All authors read and approved the final manuscript. \\ Funding \\ The authors declare that they have no conflict of interest or funding.}

\section{Availability of data and materials}

The datasets used and/or analysed during the current study are available from the corresponding author on reasonable request.

\section{Declarations}

\section{Ethics approval and consent to participate}

The study was approved by the Maccabi Healthcare Services review board (0081-2019). By answering the survey and replying back, they gave their consent to participate in the study, knowing that their response will be returned to the first author anonymously. Maccabi Healthcare Services review board approved this procedure.

\section{Consent for publication}

Not applicable.

\section{Competing interests}

All authors are currently employees of Health Maintenance Organizations. The authors declare that they have no competing interests.

\section{Author details}

${ }^{1}$ Child Development, Medical Division and Research Institute, Maccabi Healthcare Services, 27 Hamered St., 6812509 Tel Aviv, Israel.

${ }^{2}$ Kahn-Sagol-Maccabi Research and Innovation Institute, Maccabi Healthcare Services, 4 Koifmann St., 6801296 Tel Aviv, Israel. ${ }^{3}$ Clalit Child Development Center, Clalit Healthcare Services, 75 Betlehem Rd., 9362410 Jerusalem, Israel. ${ }^{4}$ Department of Environmental Health, Harvard T H Chan School of Public Health, Boston, Massachusetts, USA. ${ }^{5}$ Pediatric Neurology and Developmental Unit, Loewenstein Rehabilitation Hospital, 278 Ahuza St., 4310000 Raanana,

Israel. ${ }^{6}$ Sackler Faculty of Medicine, Tel Aviv University, Tel Aviv, Israel.

Received: 14 August 2020 Accepted: 4 March 2021

Published online: 12 March 2021

\section{References}

1. American Psychiatric Association. Diagnostic and statistical manual of mental disorders: diagnostic and statistical manual of mental disorders. 5th ed. Arlington: American Psychiatric Association; 2013.

2. Williams JG, Higgins JP, Brayne CE. Systematic review of prevalence studies of ASD spectrum disorders. Arch Dis Child. 2006;91:8-15.

3. Maenner MJ, Shaw KA, Baio J, et al. Prevalence of autism Spectrum disorder among children aged 8 years - autism and developmental disabilities monitoring network, 11 sites, United States, 2016. MMWR Surveill Summ. 2020;27(69):1-12.

4. Davidovitch M, Slobodin O, Weisskopf MG, Rotem RS. Age-Specific Time Trends in Incidence Rates of Autism Spectrum Disorder Following Adaptation of DSM-5 and Other ASD-Related Regulatory Changes in Israel. Autism Res. 2020;13:1893-1901.

5. Woodbury-Smith M, Scherer SW. Progress in the genetics of autism spectrum disorder. Dev Med Child Neurol. 2018:60:445-51.

6. Rylaarsdam L, Guemez-Gamboa A. Genetic Causes and Modifiers of ASD Spectrum Disorder. Front Cell Neurosci. 2019:13:385.

7. Modabbernia A, Velthorst E, Reichenberg A. Environmental risk factors for ASD: an evidence-based review of systematic reviews and meta-analyses. Mol ASD. 2017;8:13.

8. Graf WD, Miller G, Epstein LG, Rapin I. The autism "epidemic": ethical, legal, and social issues in a developmental spectrum disorder. Neurology. 2017;88: 1371-80.

9. Grandjean P, Landrigan PJ. Neurobehavioural effects of developmental toxicity. Lancet Neurol. 2014;13:330-8.

10. Rotem RS, Chodick G, Davidovitch M, Hauser R, Coull BA, Weisskopf MG Congenital abnormalities of the male reproductive system and risk of autism Spectrum disorders. Am J Epidemiol. 2018;1:656-63.

11. Tordjman S, Somogyi E, Coulon N, Kermarrec S, Cohen D, Bronsard G, et al. Gene $\times$ Environment interactions in autism spectrum disorders: role of epigenetic mechanisms. Front Psychiatry. 2014;5:53.

12. Raz R, Roberts AL, Lyall K, Hart JE, Just AC, Laden F, et al. Autism spectrum disorder and particulate matter air pollution before, during, and after pregnancy: a nested case-control analysis within the Nurses' health study II cohort. Environ Health Perspect. 2015;123:264-70.

13. Heffler KF, Sienko DM, Subedi K, McCann KA, Bennett DS. Association of Early-Life Social and Digital Media Experiences with Development of autism Spectrum disorder-like symptoms. JAMA Pediatr. 2020;1:690-6.

14. King $M$, Bearman P. Diagnostic change and the increased prevalence of autism. Int J Epidemiol. 2009;38:1224-34. 
15. Shattuck PT. The contribution of diagnostic substitution to the growing administrative prevalence of autism in US special education. Pediatrics. 2006;117:1028-37.

16. Coo H, Ouellette-Kuntz H, Lloyd JE, Kasmara L, Holden JJ, Lewis ME. Trends in autism prevalence: diagnostic substitution revisited. J Autism Dev Disord. 2008:38:1036-46.

17. State of Israel Ministry of Health. (2008). Providing services in the field of child development for autistic spectrum children. Available at: https://www. health.gov.l//hozer/mk03_2009.pdf. Accessed 30 July 2020.

18. Davidovitch M, Koren G, Fund N, Shrem M, Porath A. Challenges in defining the rates of ADHD diagnosis and treatment: trends over the last decade. BMC Pediatr. 2017;17:218

19. State of Israel Ministry of Health. (2007). Director General's Circular concerning the diagnosis of children suffering from autism PDD (the autism spectrum) Available at: http://www.health.gov.il/hozer/mk13_2007.pdf. Accessed 30 July 2020.

20. Wiggins LD, Rice CE, Barger B, Soke GN, Lee LC, Moody E, EdmondsonPretzel R, Levy SE. DSM-5 criteria for autism spectrum disorder maximizes diagnostic sensitivity and specificity in preschool children. Soc Psychiatry Psychiatr Epidemiol. 2019;54:693-701.

21. Bent CA, Barbaro J, Dissanayake C. Change in autism diagnoses prior to and following the introduction of DSM-5. J Autism Dev Disord. 2017:47:163-71.

22. ZERO TO THREE. (2016). DC:0-5 ${ }^{\text {TM: }}$ : diagnostic classification of mental health and developmental disorders of infancy and early childhood. Washington, DC: Author.

\section{Publisher's Note}

Springer Nature remains neutral with regard to jurisdictional claims in published maps and institutional affiliations.

Ready to submit your research? Choose BMC and benefit from:

- fast, convenient online submission

- thorough peer review by experienced researchers in your field

- rapid publication on acceptance

- support for research data, including large and complex data types

- gold Open Access which fosters wider collaboration and increased citations

- maximum visibility for your research: over $100 \mathrm{M}$ website views per year

At $\mathrm{BMC}$, research is always in progress.

Learn more biomedcentral.com/submissions 